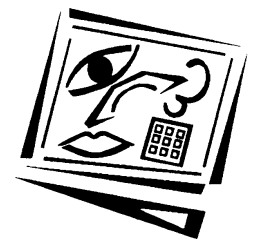

\title{
Technology enabled active learning (TEAL) in introductory physics: Impact on genders and achievement levels
}

\author{
Ruey S. Shieh \\ Kainan University \\ Wheijen Chang \\ Feng-Chia University \\ Eric Zhi-Feng Liu \\ National Central University
}

\begin{abstract}
This study explored the impact of Technology Enabled Active Learning (TEAL) on students learning general physics, focusing on differences between genders and among various achievement levels. A quasi-experimental investigation was conducted on two semesters of courses offered in 2008. Data sources consisted of pre-tests, posttests, self-report surveys, class observations, and interview data. The test results indicate that the learning gain achieved by the experimental group was $11 \%$ higher than that achieved by the control group in the first semester, though the margin decreased to $1 \%$ in the second semester. In the situation of the low achievement level, there was no difference found in the learning gain achieved by the two groups in the second semester. The qualitative data revealed that student academic performances were disclosed to be associated with the following factors: the instructors' teaching styles and instructional skills, the students' prior knowledge, their study habits, and the cohort atmosphere. That is, implementation of the innovative tool alone might not be sufficient to significantly improve student performance. Nonetheless, the interactive, collaborative instructional approach seemed to appeal to females more than it did to males, disclosing the potential of TEAL in narrowing the learning gap between genders.
\end{abstract}

\section{Introduction}

Technology Enabled Active Learning (TEAL) was developed by Massachusetts Institute of Technology (MIT) in 2001, and is an innovative teaching and learning structure, featuring a multimedia-equipped studio to facilitate large classes of students learning science and technology related courses (Dori \& Belcher, 2005, MIT Physics, n.d.). The goal of establishing TEAL is to involve students at a profound level with a more thorough understanding of the physics subject matter, both conceptually and analytically (Belcher, 2001) through integrating lectures, problem solving, and handson laboratory activities in the instruction (Breslow, 2010). TEAL emphasises group discussion and interaction during the instructional process. The group interaction and discussion is supported by a personal response system (PRS), which some educators consider to be a powerful tool for teaching science courses and large classes (e.g. Beatty \& Gerace, 2009; Beatty, et al., 2006b; Caldwell, 2007; Hancock, 2010; Ribbens, 2007). 
Kay and LeSage (2009) reviewed over 50 studies and found that the use of PRS is beneficial to promote learning motivation, cognitive engagement, and interactive with peers, as well as facilitate formative assessment.

The theoretical background of TEAL is founded on social constructivism (Dori \& Belcher, 2005). Many researchers believe that it is important to consider social, interactive, and cultural aspects of learning as part of the knowledge sharing and building process (Hara \& Kling, 2002). Wenger (1998) identified the importance of learning as social participation which has an emphasis on "the negotiation of meaning rather than on the mechanics of information transmission and acquisition" (p.265). It is through the routine negotiation of meanings, rather than the information acquisition and transmission, that members in the community learn, and thus continue their participation and engagement (Wenger, 1998). Therefore, group discussion becomes crucial in that the peer dialogue facilitates students to gradually negotiate and grasp the scientific meanings of terminologies, and to distinguish the difference between scientific definitions and daily life usages (Scott, 1998). Constructivist instruction, as opposed to the traditional transmission model, is regarded as being more likely to result in meaningful learning and understanding. Accordingly, instructors need to provide context-rich questions, along with hands-on activities, and to allow students to observe, think, and elaborate on the underlying physical principles (Sokoloff \& Thornton, 2004). Hake (1998) reported that the learning gain of students engaged in interactive instructional approaches $(0.48 \pm 0.14)$ were much higher than those involved in traditional instruction $(0.23 \pm 0.04)$ in learning physics.

TEAL was introduced to a national university in Taiwan in 2004. In 2005, the physics department began to use the TEAL studio to teach introductory physics courses (mechanics in the first semester and electromagnetism in the second semester), a prerequisite for students majoring in sciences and engineering. While collaborating with MIT, the implementation of TEAL at the university was highly similar to that implemented at MIT, both hardware-wise and software-wise. According to the study conducted by Shieh, Chang and Tang (2010), which examined the impact of TEAL on student learning in 2007, it was found that the experimental students (studying in the TEAL studio) in general showed positive attitudes toward the novel learning/teaching instructional method. They also outperformed the control students (studying in the traditional classroom) and achieved more significant learning outcomes in the second semester than in the first semester. To further explore the TEAL effect, the current study not only follows up the impact of TEAL on students learning physics, but it also investigates the impact of TEAL on genders and achievement levels in its 2008 implementation.

\section{Gender gap in learning science}

The Third International Mathematics and Science Study (TIMSS) report shows that the percentage of high achieving boys is significantly higher than that of girls on average for science achievement across countries (Martin, et al., 1999). Similarly, Zhu (2007) reported that female students' performance in physics is lower than that of male students. Pollock, Finkelstein and Kost (2007) disclosed that, in an introductory physics course taught with interactive engagement instruction, male students outperformed female students on conceptual learning. In a large-scale study conducted by Docktor and Heller (2008), in which 40 classes with more than 5,500 students taught using cooperative group problem solving in introductory physics courses were involved, it 
was found that the males significantly outperformed the females in the pre-test. However, they reported that the gender gap decreased with higher post-test scores, possibly because of a ceiling effect for the males, whereas the gap was not significantly reduced in the lower test scores.

Gender stereotyping is by no means in favour of females developing science-oriented careers. She (1998) found that most female students in Taiwan, particularly elementary and middle-school students, were incapable of picturing themselves pursuing a science-related profession due to worrying about being labeled as too competent when compared with their male peers. However, science educators have been engaged in promoting the participation rate of female students and achieving a more equitable gender balance in the past 30 years (Hodgson, 2000). The study conducted by Gilleece, Cosgrove and Sofroniou (2010) indicated that, based on the 2006 PISA (Programme for International Student Assessment) data, there were no significant gender differences in science performance in the majority of OECD countries.

Kitchenham (2002) reported that gender difference can be attributed to sociological influences, such as culture, attitude and choice, and biological influences, such as neurology, chemical and imagery. Zhu (2007) asserted that self-efficacy and teaching content design are two influencing factors affecting students' success in studying physics. According to the researcher, the incongruence of physics content selection with female students' development of cognitive psychology and social cognition contributes to the lower physics self-efficacy of female students, and consequently less course-taking interest in physics. Kost, Pollock and Finkelstein $(2008,2009)$ revealed that a gender gap exists in interactive physics classes mainly owing to differences in students' prior knowledge and their ensuing attitudes and beliefs. For example, they reported that female students were less likely to take physics in high school than male students. Hazel, Logan and Gallagher (1997) argued that females' inferior performance to males in learning science might be related to the test question types and the context within which the questions are set, in that they appear to favour male students.

Achievement differences between genders could be reduced through sound pedagogical strategies (Kitchenham, 2002); for instance, alternating between group discussion and structured instruction to accommodate different learning needs for both genders. Similarly, the European Technology Assessment Network (2000) urged that science-related gender stereotyping issues be resolved through curriculum, pedagogy, and media. Lorenzo, Crouch, and Mazur (2006) found that interactive engagement instruction, such as encouraging in-class peer interaction, effectively reduced or even eliminated the gender gap in conceptual understanding of an introductory, calculus-based physics course. Beichner, et al. (1999) reported that female students were found to be as engaged in the class discussion and group work as the male students in a highly collaborative, technology-rich, activity-based learning environment. They emphasised that socialisation among peers plays a critical role in the success of students in the physics component of the curriculum.

\section{Low and high achieving gap in learning science}

According to the National Assessment of Educational Progress (NAEP) reported by Freeland (1983), the learning gap between high and low achieving students, aged 9 and 13 , was narrowing, based on their reading, mathematics, and science test data. Lau and Chan (2001) found that the gap among under-achievers and high achievers could be 
attributed to motivational variables, such as having a low academic self-concept, low attainment value on learning, and deficiency in using learning strategies. Martin (1985) revealed that among low achievers, negative motivation, such as anxiety and frustration, is almost twice as high as that of high achievers. Bailey (1971) stated that self-estimates and desired levels of college ability are positively associated with the level of students' actual achievement.

Dori and Belcher (2005) disclosed that although students studying in a technology-rich, active learning environment improved their performance significantly, the learning gain of the low scoring group was the highest compared with the intermediate and high scoring groups. Likewise, Lorenzo, et al. (2006) revealed that interactive engagement physics courses effectively helped the female students move from the low scoring group to the high scoring group. In other words, the interactive engagement instruction effectively reduced the failure rate of the low achieving female students.

The positive impacts of interactive instructional formats on student performance, particularly on females and on low achieving students, as reported by previous literature, motivated the researchers of the current study to explore the influence of TEAL on student learning with the stated aspects in an Asian context. In addition to reporting the quantitative perspective of the results, this study also triangulates qualitative data to further examine students' learning experiences with the technologyenabled learning environment. Three research questions are addressed in this study:

- To what extent and how does TEAL impact student learning overall?

- To what extent and how does TEAL impact student learning between genders?

- To what extent and how does TEAL impact student learning among various achievement levels?

\section{Method}

\section{Research context}

A quasi-experimental research was designed to conduct the study. In 2008, there were four large classes of students studying the introductory physics course at CCU. Three of the classes, composed of two departmental classes each, studied the course in the TEAL studio and were regarded as the experimental group, whilst three departmental classes studying in the traditional setting were regarded as the control group. Although the four classes were taught by different instructors, all used uniform course materials and were tested with the same mid-term and final examination questions.

\section{Data collection and analysis}

Five types of data were collected, including:

1. Pre-test: All students studying the introductory physics course were scheduled to take the pre-test at the beginning of the semester. In the first semester, the Force Concept Inventory (FCI) developed by Hestenes, Wells and Swackhamer (1992) was used to assess the students' conceptual comprehension in mechanics. In the second semester, the questions developed by Mazur (1996) were used for evaluating the students' concepts in electromagnetism. The first test consists of 30 multiple choice questions, whereas the second test contains 40 questions. 
2. Post-test: The students were scheduled to take the post-test (the same test content as the pre-test) at the end of each semester.

3. Survey: A self-report survey was administered to all students to gather their learning experiences at the end of the second semester. Some of the survey questions, however, were modified to fit the learning environments of TEAL and the traditional classroom. For instance, in the survey conducted in the traditional class, questions related to TEAL were omitted. A 5-point Likert scale ranging from 5 (strongly agree) to 1 (strongly disagree) was used to collect the survey data. Four categories of questions were included: (1) instructional process related questions, (2) learning preference related questions, (3) self-examination questions, and (4) demographic information.

4. Class observations: Two class observations were conducted in each of the TEAL and traditional classes in both semesters to obtain the interactive, dynamic aspect of the classroom activities. The observed items consisted of (1) the students' class attendance, (2) attention to the lecture, (3) engagement in the class activities, (4) the number of questions the students asked, (5) the number of PRS questions the instructor posed, and (6) demonstrations, simulations, and hands-on experiments conducted.

5. Focus group interviews with students: group interviews were performed at the end of the second semester to acquire insights into the student's overall reactions to their learning experiences. Semi-structured questions were used to elicit the students' responses. Five categories of questions were composed, including the students' perceptions of (1) the course content, (2) the instructor's teaching style and instructional skills, (3) the use of PRS, (4) the learning environment, and (5) the course website. Students' self reflection to improve their future learning was also gathered. Both genders as well as different achievement levels (high, intermediate, and low levels) of students in both the TEAL and control classes were arbitrarily chosen for the interviews to attain multiple perspectives of the students' learning experiences. Each interview lasted 40 to 60 minutes, depending upon the extent of the students' sharing. The researcher (the first author) personally conducted the interviews.

Quantitative data were analysed using statistical tools, including descriptive statistical, t-test, and learning gain calculations. The theoretical framework of social constructivism proposed by Patton (2002) was used to analyse the qualitative data, particularly the interview data. The three types of codes, descriptive, interpretive, and pattern codes, suggested by Miles and Huberman (1994), were adopted in the coding process. The quantitative data were triangulated with the qualitative findings to explore the participants' learning experiences in depth.

\section{Results}

There were 410 students, 281 TEAL (experimental) students and 129 control (traditional classroom) students, enrolled in the four introductory, year-long physics classes in 2008. A total of 342 students (252 TEAL students and 90 control students) completed both the pre- and post-tests in the first semester, whilst 310 students (238 TEAL students and 72 control students) completed the two tests in the second semester. The comparison examinations revealed that there were no significant 
differences between the TEAL and control groups in their pre-test results, regardless of grouping categories. A total of 250 valid surveys were collected from the three TEAL classes, representing an $89 \%(250 / 281)$ return rate, and 105 (or $81 \%$ ) surveys were gathered from the control class. There were 77 students (60 TEAL students and 17 control students) participating in the 13 focus group interviews (ten with the TEAL students and three with the control students).

\section{Impact of TEAL on student learning between groups}

Table 1 displays the mean scores of the pre- and post-tests of the two groups in both semesters. In the first semester, the learning gain, $\langle\mathrm{g}\rangle$, achieved by the TEAL group (0.15) was significantly higher than that of the control group (0.02). However, the gains achieved by both groups in the second semester were only slightly different, 0.16 and 0.15 , respectively. Learning gain is defined by Hake (1998) as $<\mathrm{g}>=\{$ (post test - pre test) / (100 - pretest) $\} \%$.

Table 1: Test results by group in the two semesters

\begin{tabular}{|l|c|c|c|c|c|c|c|c|}
\hline \multicolumn{1}{|c|}{ Semester } & \multicolumn{3}{|c|}{ 1st semester } & \multicolumn{3}{c|}{ 2nd semester } \\
\hline Group & \multicolumn{2}{|c|}{ TEAL } & \multicolumn{2}{c|}{ Control } & \multicolumn{2}{c|}{ TEAL } & \multicolumn{2}{c|}{ Control } \\
\hline Pre/post test & Pre & Post & Pre & Post & Pre & Post & Pre & Post \\
\hline Mean & 75.26 & 78.85 & 73.00 & 73.59 & 43.08 & 52.09 & 43.47 & 51.98 \\
\hline Std dev. & 15.29 & 13.95 & 15.55 & 13.00 & 8.18 & 9.61 & 6.40 & 8.68 \\
\hline t-test P-value & \multicolumn{2}{|c|}{$0.00^{*}$} & \multicolumn{2}{c|}{0.58} & \multicolumn{2}{c|}{$0.00^{*}$} & \multicolumn{2}{c|}{$0.00^{*}$} \\
\hline$<$ g $>$ & \multicolumn{2}{|c|}{0.15} & \multicolumn{2}{c|}{0.02} & \multicolumn{2}{c|}{0.16} & \multicolumn{2}{c|}{0.15} \\
\hline
\end{tabular}

${ }^{*}$ P-value of the paired t-test $<0.001$

\section{The instructional process}

The survey data showed that the TEAL students in general were inclined to agree that there was more interaction taking place between the instructor and students (mean = 3.82 ) and among peers (mean $=4.18$ ) in class, when compared with their previous traditional classroom learning experiences. The traditional-class students, on the contrary, perceived a lower extent of interaction with the instructor (mean $=2.94$ ). Similarly, the TEAL students tended to agree that they were encouraged to ask questions in class (mean $=3.27$ ), whereas this was less apparent in the traditional class (mean $=2.79)$. The instructor's instructional style seemed to have affected the TEAL students (mean $=3.15$ ) to a slightly greater extent than it did for the control students (mean $=2.94)$. The TEAL students were prone to agree that they paid more attention to classes due to the use of the personal response system (mean $=3.67$ ). The majority of the students, regardless of group, however, tended to agree that taking the physics course imposed greater pressure than taking other courses (mean $=3.72$ and mean $=$ 3.52 , respectively).

The class observation data showed that attendance rates in the TEAL classes were much higher than those in the control class. The interview data revealed that the mandatory attendance policy enacted only in the TEAL classes might have encouraged the students' attendance. Many students expressed that they did not like being forced to attend the class; however, they admitted that without the mandatory policy, they would possibly come to class less often and subsequently end up with a poorer grade. The survey results showed that the attendance policy made a slight difference to the students' perception of their learning between the TEAL (mean $=3.15$ ) and the control 
(mean $=2.96)$ groups. Moreover, the interview data disclosed that the majority of the TEAL students preferred to study in the TEAL environment, rather than in a traditional classroom, mainly due to the interactive aspect of its studio design.

\section{Study habits}

The survey results disclose that the majority of students, regardless of group, in general, did not preview (or did not spend much time previewing) the course content prior to coming to class. There were, however, some differences between the hours the students spent on reviewing the course materials. More than half of the TEAL students $(57 \%)$, as opposed to $40 \%$ of the control students, spent less than 2 hours per week reviewing the course content. In addition, less than one-fifth of the TEAL students $(17 \%)$, as opposed to $31 \%$ of the control students, committed four hours or more per week to reviewing the course materials. In other words, the TEAL students, on average, spent less time studying the course materials than the control students did.

\section{Impact of TEAL on gender differences in student learning}

Table 2 shows gender differences in students' academic performance. In the first semester, the learning gains achieved are 0.15 and 0.02 by the TEAL and control males, respectively, and 0.1 and 0.03 by the TEAL and control females, respectively. In the second semester, both genders in both groups made significant improvement in their post-test. However, the learning gains achieved by the TEAL groups in both genders and by the control male group were the same, 0.15. In addition, it is noted that the learning gain achieved by the TEAL females was higher than that achieved by the TEAL males (0.18 vs. 0.15).

Table 2: Test results by gender

\begin{tabular}{|c|c|c|c|c|c|c|c|c|c|}
\hline \multirow{2}{*}{\begin{tabular}{|l} 
Semester \\
First
\end{tabular}} & \multirow{3}{*}{\begin{tabular}{|l|}
\multicolumn{1}{|r}{ Gender } \\
Group \\
Pre/Post Test \\
\end{tabular}} & \multicolumn{4}{|c|}{ Male } & \multicolumn{4}{|c|}{ Female } \\
\hline & & \multicolumn{2}{|c|}{ TEAL $(\mathrm{N}=209)$} & \multicolumn{2}{|c|}{ Control $(\mathrm{N}=66)$} & \multicolumn{2}{|c|}{ TEAL(N=43) } & \multicolumn{2}{|c|}{ Control $(\mathrm{N}=24)$} \\
\hline & & Pre & Post & Pre & Post & Pre & Post & Pre & Post \\
\hline & Mean & 75.50 & 79.28 & 74.95 & 75.35 & 74.11 & 76.74 & 67.64 & 68.75 \\
\hline & Std dev & 15.88 & 14.12 & 12.99 & 12.98 & 12.10 & 13.02 & 13.92 & 12.03 \\
\hline & t-test P-value & \multicolumn{2}{|c|}{$0.00^{*}$} & \multicolumn{2}{|c|}{0.09} & \multicolumn{2}{|c|}{0.74} & \multicolumn{2}{|c|}{0.63} \\
\hline & $\langle\mathrm{g}\rangle$ & \multicolumn{2}{|c|}{0.15} & \multicolumn{2}{|c|}{0.02} & \multicolumn{2}{|c|}{0.10} & \multicolumn{2}{|c|}{0.03} \\
\hline \multirow[t]{6}{*}{ Second } & Group & \multicolumn{2}{|c|}{ TEAL $(\mathrm{N}=198)$} & \multicolumn{2}{|c|}{ Control $(\mathrm{N}=50)$} & \multicolumn{2}{|c|}{ TEAL $(\mathrm{N}=40)$} & \multicolumn{2}{|c|}{ Control $(\mathrm{N}=22)$} \\
\hline & Pre/Post Test & Pre & Post & Pre & Post & Pre & Post & Pre & Post \\
\hline & Mean & 43.41 & 52.13 & 43.55 & 52.10 & 41.44 & 51.88 & 43.30 & 51.70 \\
\hline & Std dev & 8.52 & 9.77 & 5.15 & 8.80 & 6.04 & 8.93 & 8.74 & 8.60 \\
\hline & t-test P-value & \multicolumn{2}{|c|}{$0.00^{*}$} & \multicolumn{2}{|c|}{$0.00^{*}$} & \multicolumn{2}{|c|}{$0.00^{*}$} & \multicolumn{2}{|c|}{0.001} \\
\hline & $<\mathrm{g}>$ & \multicolumn{2}{|c|}{0.15} & \multicolumn{2}{|c|}{0.15} & \multicolumn{2}{|c|}{0.18} & \multicolumn{2}{|c|}{0.15} \\
\hline
\end{tabular}

${ }^{*}$ P-value of the paired t-test $<0.001$

\section{Study assistance}

In the survey, the students were asked to rank three items among 14 according to which they thought were most helpful for their study. The 14 items consisted of (1) the instructor's instructional style and teaching skills, (2) the use of PRS, (3) the attendance requirement (4) the instructor's after-class assistance, (5) TAs' in-class help, (6) TAs' recitation, (7) in-class small group discussion, (8) classmates' after-class assistance, (9) self study, (10) video clips posted on the web, (11) 3D simulation, (12) lab activities, (13) frequent tests, and (14) homework. For the male students, regardless of whether they 
were in the TEAL or the control group, the top two helpful items were self study and the instructor's teaching style and instructional skills. While the TEAL male students regarded the teaching assistant's in-class assistance the third helpful item, the control male students considered peers' after-class assistance as being more helpful, probably due to the unavailability of TAs in the traditional class. Although the female students also recognised self study and TAs' / peers' assistance as helpful, they did not consider the instructor's instructional style as being as influential as the males did. Rather, the TEAL females regarded the in-class small group discussions as being more helpful for their study. Consistent with the earlier literature (e.g. Whitten, Foster \& Duncombe, 2003), the females appeared to be more in favour than the males of the experimental interactive, innovative instructional approach.

\section{Perceived pedagogical strategies}

According to the class observation data, one of the differences in the instructional process between the TEAL and control classes was that there were more demonstrations and simulations presented in the TEAL classes. Students in the TEAL classes also had more opportunities to engage in small group discussions. Responding to PRS questions provided the main opportunities for the students in the TEAL classes to interact with the instructor and their small group members. The round table seat arrangement seemed to have facilitated the three-member group discussions. Some of the TEAL instructors would occasionally assign students questions to solve and then circulate the classroom to check on their progress, which did not occur in the traditional classroom. Although the TEAL classes appeared to be relatively more interactive than the traditional class, one-way lecturing basically accounted for the majority of the instructional activities.

The interview data revealed that more TEAL females than males praised the use of PRS. A number of females also regarded small group discussions as a means for developing friendships. Although most of the male students interviewed also considered the use of PRS helpful to their learning in terms of exchanging thoughts with group members, quite a few mentioned that the time allowed to them to think through the questions was too short. Subsequently, they sometimes simply followed their peers in clicking an answer, which they thought undermined the purpose of using PRS. Another concern was that the instructors tended to skip explanations when the PRS questions appeared to have high correct ratios. The students said that a question with a high correct ratio did not necessarily indicate that they had grasped the concept of the posed question. The frequency of using PRS was found to be rather different among instructors. While some instructors reportedly might raise as many as ten PRS questions in a class, some others might not use PRS at all in a whole class. Both situations were considered inappropriate by the interviewed students. In the former situation, raising ten PRS questions in a class was considered a waste of time, particularly when no discussion or explanation followed, whereas in the latter situation, when not a single question was raised in a class made "the long lecture dull" and made it "easy to doze off."

\section{Reactions to the instructional style}

Similar to the survey results reported previously, the interview data also showed that the males appeared to be more critical of the instructor's teaching style than the females. Some TEAL male students reported that their instructor was very 
knowledgeable; however, the instructor's teaching pace was simply too fast and that he "did not realise what the students actually did not understand." Likewise, another male student in a different TEAL class elaborated his learning experiences as follows:

He (the instructor) always assumed that we must have already known a lot of basic concepts prior to taking the course, which we really didn't... He always lectured for a long while without stopping. Then when he finally paused and asked us whether we had any questions about the lectured content, I felt like telling him that I had got stuck in some concepts lectured 15 minutes ago, and which really inhibited my

understanding of the following content. But could I ask him to restate the whole thing all over again? ... I felt like it was only a cliché saying "Do you have any questions?"

(Interview with focus group \#5, June. 16, 2009)

Some of the interviewed students echoed the above statements. However, some female students in the same class provided a different perspective of the instructor. One mentioned that her group once experienced the instructor's clear, patient explanations about some questions they asked when he circulated the classroom to check on students' answers to a posed question. Ironically, these clear, patient explanations were regarded as a waste of time by several male students in the same class. They said that spending time providing additional explanations to a few students, instead of the whole class, was inappropriate in that it delayed the progress of the lecture. It was not uncommon to hear students mention that they missed "the good old days" - the way their high school teachers taught, during the interview. Quite a few students said that their high school teachers often provided them with very precise, step by step explanations and notes and highlighted the key points that were likely to appear on the examinations. Unsurprisingly, it was found that the instructor whom the students praised most for his instructional style was the one who used the PRS least often. This particular instructor reportedly was more organised in delivering lectures and was better able to explain the concepts the students had difficulty comprehending.

\section{Impact of TEAL on student learning among various achievement levels}

The students' learning outcomes, based on their achievement levels, in the first semester are shown in Table 3.

Table 3: Test results by achievement level

\begin{tabular}{|c|c|c|c|c|c|c|c|c|c|c|c|c|c|}
\hline $\begin{array}{l}\text { Sem- } \\
\text { ester }\end{array}$ & Level & & $\mathrm{Hi}$ & igh & & & Intern & hediate & & & $\mathrm{Lc}$ & $\mathrm{w}$ & \\
\hline First & Group & $\begin{array}{l}\mathrm{TE} \\
(\mathrm{N}=\end{array}$ & $\begin{array}{l}\text { AL } \\
122)\end{array}$ & $\begin{array}{l}\text { Con } \\
(\mathrm{N}=\end{array}$ & $\begin{array}{l}\text { itrol } \\
=38)\end{array}$ & $\begin{array}{l}\mathrm{TE} \\
(\mathrm{N}=\end{array}$ & $\begin{array}{l}\text { AL } \\
=99 \text { ) }\end{array}$ & $\begin{array}{l}\text { Cor } \\
(\mathrm{N}=\end{array}$ & $\begin{array}{l}\text { trol } \\
=36)\end{array}$ & $\begin{array}{l}\text { TE } \\
(\mathrm{N}=\end{array}$ & $\begin{array}{l}\text { AL } \\
=31)\end{array}$ & $\begin{array}{l}\text { Con } \\
(\mathrm{N}=\end{array}$ & $\begin{array}{l}\text { trol } \\
\text { 16) }\end{array}$ \\
\hline & Test & Pre & Post & Pre & Post & Pre & Post & Pre & Post & Pre & Post & Pre & Post \\
\hline & Mean & 87.35 & 86.86 & 85.53 & 82.28 & 69.73 & 74.65 & 69.17 & 70.28 & 45.38 & 60.75 & 51.88 & 60.42 \\
\hline & Std dev & 5.14 & 7.79 & 5.66 & 8.84 & 5.86 & 12.11 & 6.08 & 11.45 & 10.91 & 15.70 & 4.03 & 10.10 \\
\hline & t-test p-value & 0.2 & 26 & & $1^{*}$ & 0.00 & $0^{* * *}$ & 0. & 27 & 0.0 & $0^{\star * *}$ & 0.0 & $0^{* *}$ \\
\hline & $\langle\mathrm{g}\rangle$ & -0 . & .04 & -0 . & 22 & 0. & 16 & 0. & 04 & 0. & 28 & 0.1 & 18 \\
\hline Second & Group & $\begin{array}{l}\mathrm{TE} \\
(\mathrm{N}=\end{array}$ & $\begin{array}{l}\text { AL } \\
=76)\end{array}$ & $\begin{array}{l}\text { Con } \\
(\mathrm{N}=\end{array}$ & $\begin{array}{l}\text { trol } \\
=19)\end{array}$ & $\begin{array}{l}\mathrm{TE} \\
(\mathrm{N}=\end{array}$ & $\begin{array}{l}\text { AL } \\
=97)\end{array}$ & $\begin{array}{l}\text { Cor } \\
(\mathrm{N}=\end{array}$ & $\begin{array}{l}\text { trol } \\
=36)\end{array}$ & $\begin{array}{l}\mathrm{TE} \\
(\mathrm{N}=\end{array}$ & $\begin{array}{l}\text { AL } \\
=65)\end{array}$ & $\begin{array}{l}\text { Con } \\
(\mathrm{N}=\end{array}$ & $\begin{array}{l}\text { trol } \\
=17)\end{array}$ \\
\hline & Test & Pre & Post & Pre & Post & Pre & Post & Pre & Post & Pre & Post & Pre & Post \\
\hline & Mean & 52.24 & 55.20 & 51.32 & 53.03 & 42.29 & 52.14 & 43.19 & 52.36 & 33.54 & 48.38 & 35.29 & 50.00 \\
\hline & Std dev & 5.03 & 10.20 & 4.03 & 7.57 & 1.93 & 8.70 & 2.04 & 9.33 & 4.39 & 9.03 & 3.17 & 8.57 \\
\hline & t-test p-value & 0.0 & $\mathrm{~J} 2^{*}$ & 0.0 & $5^{*}$ & 0.00 & $0^{* \star \star *}$ & 0.0 & $0^{* \star \star}$ & 0.00 & $0^{* \star *}$ & 0.00 & $0^{* * \star}$ \\
\hline & $<\mathrm{g}\rangle$ & 0. & 06 & 0. & 04 & 0. & 18 & 0. & 16 & 0. & 22 & 0.2 & 23 \\
\hline
\end{tabular}


In first semester, the TEAL group in all three levels performed better than their counterpart control groups, though the high level group in both the TEAL and control groups achieved a negative learning gain, -0.04 vs. -0.22 , respectively, possibly due to the ceiling effect, as Docktor and Heller (2008) contended. In the second semester, all achievement levels, regardless of groups, made significantly positive improvement in their post-test. It is, however, noted that the learning gain achieved by the TEAL low achievers (0.22) was slightly lower than that achieved by their counterpart control group (0.23). Compared to the differences in the learning gains between the TEAL and control groups in the first semester, the differences narrowed significantly in the second semester.

The survey and interview data further reveal the differences in the students' learning experiences among the three achievement levels as follows.

\section{Study commitment}

When examining the hours the students spent on reviewing the course materials, based on their academic achievement levels, it was found that the low achievers appeared to commit less effort to studying the course content than the high achievers. There were $72 \%$ of TEAL and $63 \%$ of control low achievers, as opposed to $47 \%$ and $14 \%$ of their counterpart high achievers, who spent less than two hours on reviewing the course materials. On the contrary, less than $15 \%$ of the TEAL and $8 \%$ of the control low achievers, as opposed to $28 \%$ and $43 \%$ of their counterpart high achievers, spent four hours or more reviewing the course content. The interview data also disclosed that the low achievers were more likely to develop a sense of wanting to give up the course when encountering learning bottlenecks.

\section{Prior knowledge}

The high achievers, by and large, reportedly had a stronger prior knowledge of the physics subject matter than the low achievers. Although some of the low achievers claimed to have been interested in the physics subjects and had also acquired high test scores in their high school years, they reportedly lost their learning interest in their first college year when the course content became increasingly difficult. Those who did not acquire a solid understanding of the physics concepts in their high school years appeared to be more likely to have a challenging time succeeding in the subject matter, consistent with the findings reported by Kost, et al. (2008, 2009).

\section{Reactions to the examinations}

As expected, more low achievers than high achievers regarded the test questions as being difficult. Some low achievers stated that in order to earn a passing grade in introductory physics, more effort than memorising formulas was demanded. Several, however, reported that memorising formula and practising homework questions prior to the tests were sufficient to pass the mid-term and the final examinations, because the test questions were rather similar to the homework questions. Quite a few students were somewhat dissatisfied with the type of examination questions. They said that the tests were more like mathematics tests in that most questions required complicated calculation rather than conceptual clarification. The majority of the non-physics-major students, regardless of achievement level, mentioned that they preferred to learn and to be evaluated in terms of concepts and definitions of fundamental physics ideas, 
rather than calculation-oriented questions. Besides, the course materials and the scope of the examination were perceived as being rather irrelevant to their daily life and were also not associated with the advanced courses to be taken in the future.

\section{Self reflection}

All students interviewed were asked about what improvements they would make to strengthen their academic performance in the course, if they had an opportunity to restudy it. Increasing learning commitment was the most common statement made by the students. The majority of them, especially the lower achievers, attributed their low course grades to not putting enough effort into studying for the course. When further asked about how to improve their learning effort, some said that they would preview the course content before attending the class; some stated that they would review the lectured content more thoroughly right after the class to keep up with the class pace. Many low achievers stressed that they needed to increase their study time by decreasing their participation in extra-curricular activities and/or reducing the time spent playing online games. Although some students attributed their failure to the instructor's non-proficient instructional skills, overall, most acknowledged that they themselves were the ones to blame for their poor performance.

\section{An emerging theme: Peer support and cohort atmosphere}

During the interviews, the learning experiences described by one particular group of students caught the researcher's attention. This group of students, who were all from the same departmental class, was composed of three females and four males. According to these students, many students in their class often committed to group study, and a number of them regularly went to the library to study and do homework together. That is, students in this class appeared to have a strong connection with each other. Residing in the same dormitory was said to be one of the main reasons that allowed them to get together frequently. They reported that in their class the more advanced students always solved the homework problems first and then taught other classmates. Those who learned the knack of solving the problems would then pass it on to others. The students interviewed, particularly the female students, stated that studying together not only helped resolve academic problems, but also strengthened their friendship. One student expressed that she wished to be one of the students providing answers to others as this would mean that she had become an advanced student in the class.

It was noticed that this group of students was also more active and more enthusiastic in terms of sharing their learning experiences with the interviewer during the interview. It was obvious that the students had a strong bond. Although most of the students in this group were dissatisfied with their instructor's teaching style, they reportedly had the highest average scores in the mid-term and the final examinations among the nine departmental classes. Consistently, it was found that although the pretest mean score of this class (mean $=44.27$ ) in the second semester was ranked second among the nine departmental classes, after the physics major class (mean $=45.06)$, they outperformed all the classes in the post-test $($ mean $=55.37$ vs. mean $=53)$, which was said to have surprised the instructors teaching the TEAL classes. 


\section{Discussion}

The test results indicate that the TEAL groups overall achieved higher test scores and learning gains than their counterpart control group in the first semester. However, the learning gain differences between the two groups narrowed noticeably in the second semester, from 0.11 to zero. Likewise, although the TEAL low-achievement group achieved the highest learning gain (0.28) in the first semester, the same group achieved a slightly lower mean post-test score and learning gain than its counterpart control group ( 0.22 vs. 0.23 ) in the second semester. The results are the reverse of the 2007 study reported in Shieh, et al. (2010). The TEAL group, regardless of achievement levels, was found to have spent less time studying the course materials than the control group, which presumably contributed tpartially o the narrowed learning gain between the two groups.

The male students in both the TEAL and control groups, on average, achieved higher pre-/ post-test scores than their counterpart female groups, similar to the results reported by Zhu (2007) and Pollock, et al. (2007). However, the TEAL female group surpassed the TEAL male group in their learning gain by 0.03 in the second semester. The females were found to be in favour of the interactive, collaborative learning both inside and outside the classroom, echoing the findings reported by Beichner, et al. (1999). The TEAL studio seemed to have provided a learning environment that suited the females' learning preference. Accordant with Pollock, et al.'s (2007) assertion that the learning gap could be attributed to both student and instructor effects, this study also disclosed that student performance was related to both factors, including students' prior knowledge and study commitments as well as the instructors' instructional styles and skills. The associated issues are addressed below.

The aim of establishing a technology-enabled active learning environment was to facilitate the instructors to deliver courses in a more collaborative, interactive fashion. However, the TEAL instructors in the present study were inclined to follow the traditional one-way lecturing genre, rather than designing a more active, constructivist-based instruction. Many researchers, for example, Redish, Saul and Steinberg (1998), have contended that the traditional, lecture-oriented instructional method might only encourage passive and superficial learning. Even though some instructors in the current study attempted to use some of the TEAL features, such as PRS, they did not seem to have employed the tool adequately. Consequently, the instructor who used PRS least, but was able to manage the instructional tasks more efficiently, was regarded as the most helpful instructor. This implies that students' performance might not be simply related to the innovative teaching implementation.

The situation was complicated by the various learning needs of the students and their mixed academic backgrounds. While some students appreciated the collaborative aspect of learning and expected more time to be set aside for group discussions, some others considered it a waste of time and expected more lectures to be delivered. In addition, most students, particularly non-physics major students, regarded the content learned in the courses irrelevant to their life and their future study. Many were also dissatisfied with the test questions presented in the mid-term and final examinations owing to an over-emphasis on calculation skills, instead of conceptual understanding. It seems that the issue was greatly associated with the policy of the uniform course content, mid-term and final test questions. As students with a more varied academic background (75\% of the total students) were included in the TEAL group, as opposed 
to $42 \%$ in the 2007 study, the influence of such a policy widened, which unavoidably affected the TEAL group's overall performance.

The TEAL students' passive learning attitude toward the course might contribute also to the negative learning outcomes. Exerting minimum effort to earn a passing grade appeared to be the learning objective for the majority of students. As a result, many students relied heavily on others to complete the homework tasks, including copying answers from peers. Chang (2005b) has contended that students' commitment to deep learning strategies often gives way to the adoption of superficial strategies when pursuing course grades is involved. Nonetheless, quite a few students in the current study also acknowledged that they themselves were to blame for not spending sufficient effort and time studying for the courses. To those who also lacked solid prior knowledge, the subsequent poor performance was thus not unexpected.

\section{Conclusions and recommendations}

Many researchers and educators have cautioned that integrating technology into instruction per se is a rather challenging task, particularly integrating technology into constructivist-based pedagogy. According to Ertmer (2005), it takes five to six years for teachers to develop sufficient expertise to integrate technology into constructivistbased instruction. It was the fourth year that TEAL was adopted at CCU for teaching the introductory physics courses. The fact that there is still room for the team to improve is thus not unanticipated. However, the instructors were voluntarily involved in the innovative pedagogical method, indicating their endeavours to shift their traditional teaching method to a more interactive, collaborative manner. Indeed there have been more classes delivered in the TEAL studio as the second TEAL studio was established in the sciences department in 2009. In order to help students learn more meaningfully and effectively, the instructors need to design more coherent instruction, learning activities, and pedagogical strategies.

\section{Aligning the instructional objectives with the intended goals of TEAL}

To effectively implement TEAL, the course objectives and instructional activities must be foremost aligned with the attempted goals of TEAL. That is, the instructional objectives and learning activities of the courses must be developed based on encouraging students' active learning and thinking skills. Females appeared to be more in favour than males of the interactive, collaborative instructional approach. Instructional activities should be designed in a gender sensitive, rather than neutral, approach to address females' learning needs (Lau \& Yuen, 2010). An interactive, constructivist-based instructional method, such as emphasis on small group discussions, in the current study has the potential to narrow the learning gap between genders.

\section{Designing instruction based on students' backgrounds and learning needs}

Doolittle and Camp (1999) contended that, when designing instruction, the design content and the required skills should be understood within the framework of the students' prior knowledge. Being perceptive of students' learning needs is important when implementing instructional reform (Darling-Hammond, 2000). In order to cope with students' various academic backgrounds and learning needs, customised instruction, rather than a unified syllabus and examination system, is desired. A 
unified course content and examination system mismatched the innovative teaching paradigm (Chang, 2005a). Providing contextualised examples helps students, particularly low achievement students, connect theories to real life instances.

\section{Developing adequate PRS questions and enhancing students' independent thinking skills}

PRS is a pivotal medium in implementing TEAL; therefore, designing appropriate PRS questions is important. Beatty, et al. (2006a) contended that the PRS questions need to be designed toward promoting the depth of peer discussion and should reinforce students' building of conceptual frameworks. Designing a series of questions targeting at integrating related concepts, rather than posing individual questions discretely, is suggested. In order to prevent students from blindly clicking an answer to the posed PRS question, appropriate time for them to commit to individual thinking prior to engaging in small group discussions is necessary. Students' response speed is as valuable as the response itself in assessing student understanding (Hancock, 2010).

It is also suggested that instructors randomly call upon students to share their answer as well as explain the reasoning supporting their answer to the class, to ensure students' understanding of the discussed concepts. Chang (2005a) has contended that as students begin to benefit from acquiring more profound concepts, they would acknowledge the value of the active learning approach. Similarly, the instructors may also be concerned with not being able to complete the predetermined course coverage due to lengthier discussions. Some researchers, e.g. Carbone (1998), however, have reminded us that instructors should not mistake coverage for learning, in that a longer lecture does not necessarily mean that students learn more. Rather, adequate instruction along with timely pauses for engaging students in short active, dialectic activities helps students learn more interestingly and effectively. Kanter and Konstantopoulos (2010) found that the frequency of teachers' use of inquiry-based activities was associated with improvements in students' science attitudes. Pausing three to four times to allow discussion of PRS questions in a 50-min class session, as proposed by Rao and DiCarlo (2000), is suggested, to strengthen students' level of understanding.

\section{Increasing students' study effort through encouraging cohort activities}

In addition to implementing more active, collaborative pedagogy and providing more contextualised instructional examples, designing some learning activities based on cohort effort is suggested to increase students' learning interest and engagement. As students in one of the departmental classes demonstrated, the cohort group effect imposed a rather positive influence on the class's learning atmosphere and learning outcomes. After-class activities associated with social interaction, such as reviewing course materials together, working on assignments cooperatively, and having more able students mentor their peers, help cultivate a friendly classroom atmosphere, enhance students' learning commitment, and provide instant mediation to overcome learning barriers.

\section{Recommendations for further research}

Different from earlier studies, this study adopted both quantitative and qualitative methods to investigate the impact of an innovative pedagogical approach on student learning. Even though multiple perspectives were considered, some other aspects were 
still overlooked. For example, the instructors' voices were not investigated in the current study for their reflections and perspectives on implementing the technologyenhanced pedagogical innovation. In addition, the pre-/post-test results collected in the current and the previous year show that the FCI test used in the first semester appears to be too easy to evaluate the students' conceptual understanding of mechanics. The students were found to have attained relatively high mean scores (higher than 70) in both the pre- and post-tests. Furthermore, 20\% and 25\% of the students acquired scores higher than 90 in the pre-test and post-test, respectively.

In recent years the notions of "misconceptions of force" presented in the test have been addressed in most contemporary physics textbooks in Taiwan, which might have helped the students greatly in obtaining more robust concepts of mechanics. In other words, although FCI is a tool commonly used by international researchers, it does not seem to be appropriate for examining undergraduate students' fundamental concepts of mechanics in Taiwan. Other tools containing a wider scope of learning demands, such as the MBT developed by Hestenes and Wells (1992), may be a better alternative to suit the purpose. Due to arbitrary assignment of the experimental and control classes, the sample sizes of the two groups appear somewhat uneven, which might have distorted the statistical results reported in the study. These gaps will rely on future studies to address.

\section{Acknowledgment}

The research was sponsored by the National Science Council, NSC 97-2511-S-271-001.

\section{References}

Bailey, R. C. (1971). Self-concept differences in low and high achieving students. Journal of Clinical Psychology, 27(2), 188-191. http: / / psycnet.apa.org/psycinfo/1971-27755-001

Beatty, I. D. \& Gerace, W. J. (2009). Technology-enhanced formative assessment: A researchbased pedagogy for teaching science with classroom response technology. Journal of Science Education and Technology, 18(2), 146-162. http: / / www.springerlink.com/ content/ j878737x4421u753/

Beatty, I. D., Gerace, W. J., Leonard, W. J. \& Dufresne, R. J. (2006a). Designing effective questions for classroom response system teaching. American Journal of Physics, 74(1), 31-39. http: / / srri.umass.edu / files / beatty-2006deq.pdf

Beatty, I. D., Leonard, W. J., Gerace, W. J. \& Dufresne, R. J. (2006b). Question driven instruction: Teaching science (well) with an audience response system. In D. A. Banks (Ed.), Audience response systems in higher education: Applications and cases (pp. 96-115). Hershey, PA: Idea Group. [preprint verified 22 Oct 2011]

http: / / www.colorado.edu/MCDB / MCDB6440/Beatty2006qdi.pdf

Beichner, R., Bernold, L., Burniston, E., Dail, P., Felder, R., Gastineau, J., Gjersten, M. \& Risley, J. (1999). Case study of the physics components of an integrated curriculum. American Journal of Physics, 67(7), S16-S24. http:/ / www.ncsu.edu/per/Articles / 04IMPEC_AJP.pdf

Belcher, W. J. (2001). Studio physics at MIT. MIT Physics Annual Report 2001. [verified 22 Oct 2011]. http:/ / web.mit.edu/physics / news / physicsatmit/physicsatmit_01_teal.pdf

Breslow, L. (2010). Wrestling with pedagogical change: The TEAL initiative at MIT. Change: The Magazine of Higher Learning, 42(5), 23-29. http: / / www.changemag.org/Archives/Back\%20 Issues / September-October\%202010/wrestling-pedagogical-abstract.html 
Caldwell, J. (2007). Clickers in the large classroom: Current research and best-practice tips. Life Sciences Education, 6(1), 9-20.

http: / / comets.wisc.edu/clickers / resources / articles / CaldwellOnClickers.pdf

Carbone, E. (1998). Teaching large classes: Tools and strategies. Thousand Oaks, CA: Sage.

Chang, W. (2005a). The rewards and challenges of teaching innovation in university physics: 4 years' reflection. International Journal of Science Education, 27(4), 407-425. http: / / dx.doi.org/10.1080/0950069042000323728

Chang, W. (2005b). Impact of constructivist teaching on students? Beliefs about teaching and learning in introductory Physics. Canadian Journal of Science, Mathematics and Technology Education, 5(1), 85-99. http:/ / dx.doi.org/10.1080/14926150509556646

Darling-Hammond, L. (2000). Teacher quality and student achievement: A review of state policy evidence. Education Policy Analysis Archives, 8(1), 1-44. http: / / epaa.asu.edu/ojs/article/viewFile/392/515

Docktor, J. \& Heller, K. (2008). Gender differences in both Force Concept Inventory and introductory physics performance. In C. Henderson, M. Sabella \& L. Hsu (Eds), AIP Conference Proceedings Vol. 1064: 2008 Physics Education Research Conference (pp. 15-18). Melville, NY: American Institute of Physics. http: / / groups.physics.umn.edu / physed/Talks/Docktor_Heller_PERC08.pdf

Doolittle, P. E. \& Camp, W. G. (1999). Constructivism: The career and technical education perspective. Journal of Vocational and Technical Education, 16(1), 23-46. http: / / scholar.lib.vt.edu/ ejournals/JVTE/v16n1/ doolittle.html

Dori, Y. J. \& Belcher, J. (2005). How does technology-enabled active learning affect undergraduate students' understanding of electromagnetism concepts? The Journal of the Learning Sciences, 14(2), 243-279. http:/ / www.jstor.org/pss/25473479

Ertmer, P. A. (2005). Teacher pedagogical beliefs: The final frontier in our quest for technology integration? Educational Technology Research and Development, 53(4), 25-39. http: / / www.springerlink.com/ content/26736pvw54484187 /

European Technology Assessment Network (2000). Promoting excellence through mainstreaming gender equality. Science Policies in the European Union Report. [viewed 21 Jan 2011]. ftp:/ / ftp.cordis.europa.eu/pub/improving/ocs/_wo_etan_en_200101.pdf

Freeland, S. (1983). NAEP (National Assessment of Educational Progress) report. Education Digest, 48(8), 65. [correctness of reference uncertain 20 Nov 2011] http:/ / eric.ed.gov/ERICWebPortal/search/detailmini.jsp?_nfpb=true\&_\&ERICExtSearch_S earchValue_0=ED406223\&ERICExtSearch_SearchType_0=no\&accno=ED406223

Gilleece, L., Cosgrove, J. \& Sofroniou, N. (2010). Equity in mathematics and science outcomes: Characteristics associated with high and low achievement on PISA 2006 in Ireland. International Journal of Science and Mathematics Education, 8(3), 475-496. http: / / www.springerlink.com/ content/np1773236w3821kk/

Hake, R. R. (1998). Interactive-engagement versus traditional methods: A six-thousand- student survey of mechanics test data for introductory physics course. American Journal of Physics, 66(1), 64-74. http:/ / web.mit.edu/rsi/www/2005/misc/minipaper/papers/Hake.pdf

Hancock, T. M. (2010). Use of audience response systems for summative assessment in large classes. Australasian Journal of Educational Technology, 26(2), 226-237. http: / / www.ascilite.org.au/ajet/ajet26/hancock.html

Hara, N. \& Kling, R. (2002). Communities of practice with and without information technology. Proceedings of the American Society for Information Science and Technology, 39(1), 338-349. http: / / onlinelibrary.wiley.com/doi / 10.1002/ meet.1450390137/ full 
Hazel, E., Logan, P. \& Gallagher, P. (1997). Equitable assessment of students in physics: Importance of gender and language background. International Journal of Science Education, 19(4), 381-392. http: / / www.tandfonline.com/doi/abs/10.1080/0950069970190402

Hestenes, D. \& Wells, M. (1992). A mechanics baseline test. The Physics Teacher, 30(3), 159-166. http: / / modeling.asu.edu/r\%26e/MechBaseline.pdf

Hestenes, D., Wells, M. \& Swackhamer, G. (1992). Force Concept Inventory. The Physics Teacher, 30(3), 141-158. http: / / modeling.asu.edu / r\%26e/fci.pdf

Hodgson, B. (2000). Women in science - or are they? Physics Education, 35(6), 451-53. http: / / iopscience.iop.org/0031-9120/35/6/313/pdf/0031-9120_35_6_313.pdf

Kanter, D. E. \& Konstantopoulos, S. (2010). The impact of a project-based science curriculum on minority student achievement, attitudes, and careers: The effects of teacher content and pedagogical content knowledge and inquiry-based practices. Science Education, 94(5), 855-887. http: / / onlinelibrary.wiley.com/doi/ 10.1002/ sce.20391/ full

Kay, R. H. \& LeSage, A. (2009). A strategic assessment of audience response systems used in higher education. Australasian Journal of Educational Technology, 25(2), 235-249. http: / / www.ascilite.org.au/ajet/ajet25/kay.html

Kitchenham, A. (2002). Vive la difference: Gender, motivation and achievement. School Libraries in Canada, 22(2), 34-37.

Kost, L. E., Pollock, S. J. \& Finkelstein, N. D. (2008). The persistence of the gender gap in introductory physics. In C. Henderson, M. Sabella \& L. Hsu (Eds), Physics Education Research Conference (pp.139-142). Edmonton, Alberta, Canada: American Institute of Physics. http: / / www.colorado.edu/UCB / AcademicAffairs/ScienceEducation/images / Persistence_o f_the_Gender_Gap_in_Introductory_Physics.pdf

Kost, L. E., Pollock, S. J. \& Finkelstein, N. D. (2009). Characterizing the gender gap in introductory physics. Physical Review Special Topics - Physics Education Research, 5(010101), 114. http: / / prst-per.aps.org/abstract/ PRSTPER/v5 /i1 / e010101

Lau, K. L. \& Chan, D. W. (2001). Motivational characteristics of under-achievers in Hong Kong. Educational Psychology: An International Journal of Experimental Educational Psychology, 21(4), 417-30. http:/ / www.tandfonline.com/doi/abs/10.1080/01443410120090803

Lau, W. W. F. \& Yuen, A. H. K. (2010). Gender differences in learning styles: Nurturing a gender and style sensitive computer science classroom. Australasian Journal of Educational Technology, 26(7), 1090-1103. http: / / www.ascilite.org.au/ajet/ajet26/lau.html

Lorenzo, M., Crouch, C. H. \& Mazur, E. (2006). Reducing the gender gap in the physics classroom. American Journal of Physics, 74(2), 118-122. http:/ / dx.doi.org/10.1119/1.2162549

Martin, D. M. (1985). Relationship of motivational differences of male and female community college students to academic achievement. Abstract, Masters Thesis, University of Missouri- Kansas City. (ED262856). http:/ / eric.ed.gov / ERICWebPortal/ detail?accno=ED262856

Martin, M. O, Mullis, I. V., Gonzales, E. J., O'Connor, K. M., Chrostowski, S. J., Gregory, K. D. et al. (1999). Science Benchmarking Report: TIMSS 1999 - Eight grade, achievement for U.S. states and districts in an international context. IEA The Third International Mathematics and Science Study, MA: Boston College.

Mazur, E. (1996). Peer instruction: A users' manual. Upper Saddle River, NJ, Prentice Hall.

Miles, M. B. \& Huberman, A. M. (1994). An expanded sourcebook: Qualitative data analysis (2nd Ed.). Thousand Oaks, CA: Sage Publications.

MIT Physics (n.d.) Visualizing electricity and magnetism at MIT. http: / / web.mit.edu / 8.02t/www / 802TEAL3D / teal_tour.htm 
Patton, M. Q. (2002). Qualitative research E evaluation methods. Thousand Oaks, CA: Sage Publications.

Pollock, S. J., Finkelstein, N. D. \& Kost, L. E. (2007). Reducing the gender gap in the physics classroom: How sufficient is interactive engagement? Physical Review Special Topics - Physics Education Research, 3(010107), 1-4. http: / / www.compadre.org/portal/items/detail.cfm?ID=7562

Rao, S. P. \& DiCarlo, S. E. (2000). Peer instruction improves performance on quizzes. Advances in Physiology Education, 24, 51-55. http: / / www.cib.espol.edu.ec/Digipath/D_Papers/42368.pdf

Redish, E. F., Saul, J. \& Steinberg, R. N. (1998). Student expectations in introductory physics. American Journal of Physics, 66(3), 212-224.

http: / / web.mit.edu/rsi/www/2005/misc/minipaper/papers/MPEX.pdf

Ribbens, E. (2007). Why I like clicker personal response systems. Journal of College Science Teaching, 37(2), 3. http:/ / learningcenter.nsta.org/ product_detail.aspx?id=10.2505/4/jcst07_037_02_60

Scott, P. H. (1998). Teacher talk and meaning making in science classrooms: A Vygotskian analysis and review. Studies in Science Education, 32(1), 45-80. http: / / dx.doi.org/10.1080/03057269808560127

She, H. C. (1998). Gender and grade level differences in Taiwan students' stereotypes of science and scientists. Research in Science E Technological Education, 16(2), 125-135. http:/ / www.tandfonline.com/ doi/abs/10.1080/0263514980160203

Shieh, R. S., Chang, W. \& Tang, J. (2010). The impact of implementing technology-enabled active learning (TEAL) in university physics in Taiwan. The Asia-Pacific Education Researcher, 19(3), 401-415. http: / / ejournals.ph/index.php?journal=TAPER\&page=index

Sokoloff, D. \& Thornton, R. (2004). Interactive lecture demonstrations: Active learning in introductory physics. Wiley: Hoboken, NJ.

Wenger, E. (1998). Communities of practice: Learning, meaning, and identity. New York: Cambridge University Press, Cambridge.

Whitten, B., Foster, S. \& Duncombe, M. (2003). What works for women in undergraduate physics? Physics Today, September, 46-51. http:/ / physicstoday.org/journals/doc/PHTOAD$\mathrm{ft} /$ vol_56/iss_9/46_1.shtml?bypassSSO=1

Zhu, Z. (2007). Learning content, physics self-efficacy, and female students' physics coursetaking. International Education Journal, 8(2), 204-212.

http: / / ehlt.flinders.edu.au/education/iej/articles/v8n2/Zhub/ paper.pdf

Authors: Ruey S. Shieh, Department of Information Management

Kainan University, Taoyuan, Taiwan. Email: rueys99@gmail.com

Wheijen Chang, Physics Teaching and Research Centre

Feng-Chia University, Taichung, Taiwan. Email: wjchang@fcu.edu.tw

Eric Zhi-Feng Liu, Graduate Institute of Learning and Instruction

National Central University, Taoyuan, Taiwan. Email: totem@cc.ncu.edu.tw

Please cite as: Shieh, R. S., Chang, W. \& Liu, E. Z.-F. (2011). Technology enabled active learning (TEAL) in introductory physics: Impact on genders and achievement levels. Australasian Journal of Educational Technology, 27(7), 1082-1099.

http: / / www.ascilite.org.au/ajet/ajet27/ shieh.html 